\title{
PENERAPAN METODE PEMBELAJARAN TEAM BASED LEARNING TERHADAP PENGETAHUAN, SIKAP DAN TINGKAT PARTISIPASI MAHASISWA PRODI DIII KEPERAWATAN AKES KARYA HUSADA YOGYAKARTA
}

\author{
Pritta Yunitasari ${ }^{1}$ Elizabeth E.Iswantiningsih ${ }^{2}$ \\ prittayunitasari@gmail.com
}

\begin{abstract}
ABSTRAK
Latar Belakang :Akademi Kesehatan Karya Husada Yogyakarta tengah berupaya memperbaiki sistem pembelajaran Diploma III Keperawatan dengan mengembangkan metode pembelajaran team based learning. Penelitian ini bertujuan melihat pengetahuan dan sikap mahasiswa terhadap metode pembelajaran team based learning dan tingkat partisipasi mahasiswa dalam proses pembelajaran team based learning.
\end{abstract}

Metode : Penelitian ini menggunakan metode kuantitataif dengan rancangan penelitian adalah crosssectional. Responden penelitian ini adalah mahasiswa semester V Prodi DIII Keperawatan AKES Karya Husada Yogyakarta berjumlah 53 orang.

Hasil : Hasil penelitian menunjukan bahwa tingkat partisipasi mahasiwa dalam proses belajar mengajar team based learning dalam kategori bagus. Responden yang mempunyai partisipasi yang bagus sebanyak 71,2 persen dan mahasiswa yang tingkat partisipasinya kurang bagus sebanyak 28,8 persen. Hasil uji chi square menunjukkan bahwa pengetahuan maupun sikap mengenai metode pembelajaran TBL berpengaruh terhadap tingkat partisipasi mahasiswa $(\mathrm{p}<0,05)$. Sebagian besar responden yang mempunyai pengetahuan dan sikap yang baik, mempunyai tingkat partisipasi yang baik dalam proses pembelajaran dengan metode TBL.

Kesimpulan : Mahasiswa Akes Karya Husada Yogyakarta mempunyai pengetahuan dan sikap yang baik mengenai proses belajar mengajar dengan metode pembelajaran team based learning, Tingkat partisipasi mahasiswa dalam proses belajar mengejar dengan metode team based learning bagus. Pengetahuan dan sikap mengenai metode pembelajaran team based learning mempengaruhi tingkat partisipasi mahasiswa dalam proses pembelajaran.

Kata kunci : Pengetahuan, Sikap, Tingkat Partisipasi, Team Based Learning 


\title{
THE APPLICATION OF TEAM BASED LEARNING METHOD TOWARDS KNOWLEDGE, ATTITUDES AND PARTICIPATION OF STUDENTS' LEVEL PRODI DIII NURSING AKES KARYA HUSADA YOGYAKARTA
}

\author{
Pritta Yunitasari ${ }^{1}$ Elizabeth E.Iswantiningsih ${ }^{2}$ \\ prittayunitasari@gmail.com
}

\begin{abstract}
Background: Akademi Kesehatan Karya Husada Yogyakarta is trying to improve the learning system of Diploma III of Nursing by developing the learning method of team based learning. The aim of this study is to know the knowledge and students' interest toward the learning method of team based learning and the participation level of the student in the learning process of team based learning.
\end{abstract}

Method: This research uses quantitative method with cross-sectional study design. The respondents of this research are 53 students in fifth semester Prodi DIII Nursing AKES Karya Husada Yogyakarta.

Results: The results showed that the level of student participation in teaching and learning process based on learning team in good category. The respondents who had good participation were $71.2 \%$ and students with low participation rate of $28.8 \%$. The result of chi square test showed that knowledge and attitude about TBL learning method influenced students' participation rate $(\mathrm{p}<0,05)$. Most of respondents who have knowledge and good attitude also have a good level of participation in the learning process with the TBL method.

Conclusion: The students of Akes Karya Huasada have good knowledge and attitude during the teaching and learning process by using team based learning method. The level of student participation in learning process is pursued by good team based learning method. The knowledge and attitude about the learning method of team based learning influence students' participation level in learning process.

Keywords: Knowledge, Attitude, Level of Participation, Team Based Learning 


\section{PENDAhuluan}

Perbaikan metode pendidikan perlu terus dikembangkan terutama dalam sistem pembelajaran Diploma III Keperawatan di Indonesia, mengingat angka kelulusan hasil uji kompetensi Diploma III Keperawatan belum optimal. Salah satu penyebabnya adalah sistem pembelajaran di Diploma III Keperawatan kebanyakan masih menggunakan metode konvensional. Sistem pembelajaran konvensional menyebabkan rendahnya motivasi belajar mahasiswa ${ }^{1}$.

Metode pembelajaran team based learning merupakan salah satu metode pembelajaran yang saat ini banyak digunakan oleh berbagai perguruan tinggi di negara-negara maju, termasuk di Indonesia. Hasil penelitian terdahulu membuktikan bahwa pembelajaran dengan metode pembelajaran team based learning dapat meningkatkan belajar mahasiswa dalam kerjasama kelompok, mahasiswa sangat terlibat dalam proses kegiatan belajar, hasilnya sangat signifikan bagi mahasiswa dengan menggunakan metode pembelajaran team based learning dari pada menggunakan metode pembelajaran konvensional ( teacher centered learning ) ${ }^{2}$. Metode team based learning lebih menarik minat mahasiswa karena mahasiswa dapat belajar lebih efektif dan bekerja sama dalam tim dengan baik ${ }^{3}$.

AKES Karya Husada Yogyakarta tengah berupaya memperbaiki sistem pembelajaran Diploma III Keperawatan dengan mengembangkan metode pembelajaran team based learning. Hasil penelitian penerapan metode pembelajaran team based learning AKES Karya Husada Yogyakarta menemukan bahwa metode tersebut mampu memotivasi mahasiswa sehingga hasil belajar mahasiswa lebih baik dibandingkan metode pembelajaran ceramah. Penelitian tersebut lebih memfokuskan pada perbandingan efektifitas metode pembelajaran team based learning dengan metode ceramah dalam meningkatkan motivasi dan hasil belajar mahasiswa.
Penelitian tersebut kurang mengekplorasi mengenai proses metode pembelajaran team based learning diterapkan. Dalam manajemen mutu, proses menjadi fokus perhatian karena harus dikendalikann agar dapat mempertahankan keunggulan atau meningkatkan kinerja total dari suatu proses $^{3}$. Oleh karenanya, proses metode pembelajaran team based learning perlu dikaji mendalam untuk perbaikan dalam penerapan selanjutnya, terutama berkaitan dengan partisipasi mahasiswa dalam diskusi kelompok.

Berdasarkan uraian tersebut di atas, peneliti menganggap perlu adanya perubahan pada strategi pembelajaran di Akademi Kesehatan Karya Husada Yogyakarta dan melakukan penelitian tentang "Penerapan metode pembelajaran Team Based Learning terhadap pengetahuan, sikap dan tingkat partisipasi Mahasiswa DIII Keperawatan Akademi Kesehatan Karya Husada Yogyakarta“.

\section{METODE PENELITIAN}

Penelitian ini menggunakan metode kuantitataif dengan rancangan penelitian adalah cross-sectional. Jumlah sampel penelitian ini sebanyak 53 mahasiswa yang mengikuti mata kuliah Keperawatan Gerontik tahun ajaran 2016/2017. Metode pembelajaran mata kuliah tersebut menggunakan metode Team Based Learning. Instrumen penelitian ini menggunakan kuisioner dan lembar observasi. Kuisioner disusun sendiri oleh peneliti dan telah diuji validitas dan reliabelitasnya. Kuisioner digunakan untuk mengukur pengetahuan dan sikap mahasiswa terhadap metode pembelajaran Team Based Learning. Lembar observasi digunakan untuk mengukur partisipasi mahasiswa pada mata kuliah Keperawatan Gerontik.

\section{HASIL DAN PEMBAHASAN \\ a. Karakteristik Responden}


Penelitian ini diikuti 52 mahasiswa mata kuliah Keperawatan Gerontik yang memenuhi kriteria inklusi-ekslusi responden. Adapun karakteristik responden tercantum berikut.

Tabel 1. Distribusi Frekuensi Karakteristik Responden

\begin{tabular}{|c|c|c|}
\hline $\begin{array}{l}\text { Karakteristik } \\
\text { Responden }\end{array}$ & & \\
\hline $\begin{array}{ll} & \text { Jenis Kelamin } \\
\text { - } & \text { Laki-laki } \\
\text { - } & \text { Perempuan }\end{array}$ & $\begin{array}{l}17 \\
35\end{array}$ & $\begin{array}{l}32,7 \\
67,3\end{array}$ \\
\hline $\begin{array}{l}\text { Umur } \\
\text { - } 18 \text { Tahun } \\
\text { - } 19 \text { Tahun } \\
\text { - } 20 \text { Tahun } \\
\text { - } 21 \text { Tahun } \\
\text { - } 22 \text { Tahun }\end{array}$ & $\begin{array}{l}1 \\
6 \\
29 \\
13 \\
3\end{array}$ & $\begin{array}{l}1,9 \\
11,5 \\
55,8 \\
25,0 \\
5,8\end{array}$ \\
\hline $\begin{array}{ll} & \text { Pendidikan } \\
& \text { Sebelumnya } \\
\text { - } & \text { SMA/MA } \\
\text { - } & \text { SMK Non Keehatan } \\
\text { - } & \text { SMK Kesehatan }\end{array}$ & $\begin{array}{l}37 \\
3 \\
12\end{array}$ & $\begin{array}{l}71,2 \\
5,8 \\
23,1\end{array}$ \\
\hline $\begin{array}{ll} & \text { Daerah Asal } \\
\text { - } & \text { DIY } \\
\text { - } & \text { Non DIY }\end{array}$ & $\begin{array}{l}38 \\
14\end{array}$ & $\begin{array}{l}73,1 \\
26,9\end{array}$ \\
\hline
\end{tabular}

Sumber : Data Primer

Proporsi responden yang berjenis kelamin perempuan lebih banyak $(67,3 \%)$ dibandingkan responden yang berjenis kelamin laki-laki (32,7\%). Kebanyakan mereka berusia antara 20-21 tahun $(88,8 \%)$ dengan pendidikan sebelumnya kebanyakan SMA/MA $(73,1 \%)$. Mereka umumnya mahasiswa dari laur daerah DIY.

\section{b. Pengetahuan dan Sikap Mahasiswa mengenai Pembelajaran TBL}

Persepsi dan sikap mahasiswa mengenai strategi pembelajaran TBL diukur dengan kuisioner. Penilaian persepsi dan sikap dilakukan dengan memberi skor dari 1-4 skala likert. Jumlah penilaian responden setiap item dibagi jumlah soal. Hasil perhitungan tersebut dikategorikan menjadi 2 kelompok seperti termuat dalam tabel berikut.

Tabel 2. Distribusi Frekuensi Variabel

Penelitian

\begin{tabular}{llll}
\hline & Variabel & N & $\%$ \\
\hline & Pengetahuan & & \\
mengenai TBL & 12 & 23,1 \\
- Kurang Bagus & 40 & 76,9 \\
- Bagus & & \\
\hline Sikap mengenai TBL & & \\
- Kurang Bagus & 15 & 28,8 \\
- Bagus & 37 & 71,2 \\
\hline
\end{tabular}

Sumber : Data Primer

Responden yang mempunyai pengetahuan yang bagus tentang kegiatan belajar mengajar dengan strategi TBL sebanyak 76,9 persen. Responden yang mempunyai pengetahuan yang kurang bagus tentang kegiatan belajar mengajar dengan strategi TBL sebanyak 23,1 persen. Hal tersebut berarti sebagian besar mahasiswa telah mengetahui kegiatan belajar mengajar dengan strategi TBL.

Responden yang mempunyai sikap yang bagus tentang kegiatan belajar mengajar dengan strategi TBL sebanyak 71,2 persen dan sikap yang kurang bagus tentang kegiatan belajar mengajar dengan strategi TBL sebanyak 28,8 persen. Hal tersebut berarti sebagian besar mahasiswa mempunyai sikap yang baiik terhadap kegiatan belajar mengajar dengan strategi TBL.

\section{c. Tingkat Partisipasi Mahasiswa dalam Proses Pembelajaran TBL}

Partisipasi mahasiswa dalam proses TBL dinilai dengan ceklis kegiatan mahasiswa dalam proses pembelajaran melalui observasi. Penilaian tingkat partisipasi mahasiswa menggunakan skala likert dengan memberi skor dari 1-10. Hasil perhitungan tersebut termuat dalam tabel berikut. 
Tabel 3. Partisipasi Mahasiswa dalam Pembelajaran TBL

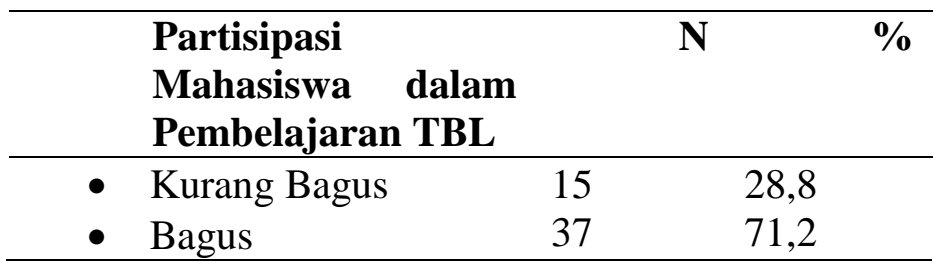

Sumber : Data Primer

Tabel di atas menunjukkan bahwa tingkat partisipasi mahasiwa dalam proses belajar mengajar TBL dalam kategori bagus. Responden yang mempunyai partisipasi yang bagus sebanyak 71,2 persen dan mahasiswa yang tingkat partisipasinya kurang bagus sebanyak 28,8 persen.

\section{d. Pengaruh Pengetahuan dan Sikap terhadap Partisipasi}

Untuk mengetahui pengaruh pengetahuan dan sikap mahasiswa mengenai strategi pembelajaran TBL terhadap tingkat partisipasi mahasiswa pada proses belajar mengajar dijelaskan dalam tabel berikut

Tabel 4. Pengetahuan dan Sikap Mahasiswa mengenai Strategi Pembelajaran TBL berdasar Tingkat partisipasi dalam proses Belajar Mengajar

\begin{tabular}{|c|c|c|c|c|c|c|}
\hline \multirow{2}{*}{ Variabel } & \multicolumn{4}{|c|}{$\begin{array}{l}\text { Tingkat } \\
\text { Partisipasi }\end{array}$} & & \\
\hline & & & Ba & & & \\
\hline $\begin{array}{ll} & \text { Pengetah } \\
\text { uan } \\
\text { - } \\
\text { Kurang } \\
\text { Bagus } \\
\text { - } \quad \text { Bagus } \\
\end{array}$ & $\begin{array}{l}8 \\
7\end{array}$ & $\begin{array}{l}53,3 \\
46,7\end{array}$ & $\begin{array}{l}4 \\
33\end{array}$ & $\begin{array}{l}10,8 \\
89,2\end{array}$ & 10,105 & 0,001 \\
\hline $\begin{array}{ll} & \text { Sikap } \\
\text { - } & \text { Kurang } \\
& \text { Bagus } \\
\text { - } & \text { Bagus } \\
\end{array}$ & $\begin{array}{l}9 \\
6\end{array}$ & $\begin{array}{l}60,0 \\
40,0\end{array}$ & $\begin{array}{l}6 \\
31\end{array}$ & $\begin{array}{l}16,2 \\
83,8\end{array}$ & 9,490 & 0,002 \\
\hline
\end{tabular}

Sumber : Data Primer
Hasil uji chi square menunjukkan bahwa pengetahuan maupun sikap mengenai metode pembelajaran TBL berpengaruh terhadap tingkat partisipasi mahasiswa $(\mathrm{p}<0,05)$. Sebagian besar responden yang mempunyai pengetahuan dan sikap yang baik mempunyai tingkat partisipasi yang baik dalam proses pembelajaran dengan metode TBL.

\section{PEMBAHASAN}

Pengetahuan mahasiswa mengenai metode pembelajaran TBL cukup baik. Sebanyak 75 persen lebih mempunyai pengetahuan mengenai TBL yang bagus. Pengetahuan tentang TBL merupakan pengetahuan mahasiswa terhadap berbagai aspek yang menyangkut TBL berupa proses TBL, peran Mahasiswa dan Dosen dalam TBL sehingga membentuk perilaku mahasiswa dalam kegiatan belajar mengajar yang menggunakan metode TBL. Pengetahuan mahasiswa terseburt diperoleh dari penjelasan dosen tentang TBL dan pengalaman mahasiswa dalam proses TBL. Hal tersebut dapat dipahami bahwa sebelum proses pembelajatran Dosen telah menjelaskan metode yang pembelajaran yang akan digunakan dan mengenai tehnis proses pembelajarannya. Metode pembelajaran merupakan salah satu faktor yang mempengaruhi hasil belajar.Pemilihan metode pembelajaran yang akan digunakan oleh guru harus sesuai dengan kondisi pembelajaran baik tujuan pembelajaran dan karakteristik bidang studi ${ }^{5}$.

Pengetahuan mengenai proses pembelajaran penting diketahui mahasiswa karena proses pembelajaran adalah proses interaksi peserta didik dengan pendidik dan sumber belajar pada suatu lingkungan belajar. Dalam tahapan introduksi, dosen mempunyai peran yang dominan karena dosen yang menyusun perencanaan semua program pembelajaran dan wajib dijelaskan kepada peserta didik. Seorang guru yang efektif seyogyanya mampu mengkomunikasikan tujuan dan 
ekspektasinya dalam proses pembelajaran kepada siswanya ${ }^{6}$.

Proses pembelajaran di sekolah merupakan kegiatan yang terprogram. Introduksi program pembelajaran harus dilakukan sebelum program pembelajaran dilakukan. Introduksi sebelum kegiatan pembelajaran bertujuan agar peserta didik mengetahui program kegiatan yang akan dilakukan sehingga menimbulkan sikap positif peserta didik serta mendorong peserta didik untuk berpartisipasi dalam proses pembelajaran.

Sikap mahasiswa mengikuti proses pembelajaran dengan metode TBL juga baik. Sekitar 70 persen responden mempunyai sikap yang baik terhadap proses pembelajaran dengan metode pembelajaran TBL. Sikap dapat dirumuskan sebagai kecenderungan untuk merespon (secara positif atau negatif) terhadap orang, objek atau situasi tertentu ${ }^{7}$. Dalam penelitian ini, sikap yang dimaksud adalah sikap mahasiswa terhadap proses belajar mengajar dengan metode TBL. Sikap mengandung suatu penilaian emosional (senang, benci, sedih dsb), disamping komponen pengetahuan tentang objek serta aspek kecenderungan bertindak.

Seorang siswa membutuhkan alasan untuk berpartisipasi di pelajaran tertentu dan mereka perlu tahu apa yang diharapkan dari pelajaran ${ }^{6}$. Introduksi bertujuan memotivasi mahasiswa berpartisipasi dalam pembelajaran. Perilaku guru di awal pembelajaran memiliki pengaruh penting pada kemauan, motivasi, dan pembentukan keyakinan siswa untuk bekerjasama dan tetap bertahan pada tugas belajarnya.

$$
\text { Sekitar } 71 \text { persen responden }
$$
mempunyai tingkat partisipasi yang baik. Hal tersebut menunjukkan bahwa dengan metode TBL tingkat partisipasi mahasiswa cukup baik. Partisipasi adalah kemampuan siswa untuk terlibat aktif secara mental dan emosional dalam proses pembelajaran ${ }^{8}$. Partisipasi siswa saat proses pembelajaran sangat penting karena siswa yang berpartisipasi baik di setiap proses pembelajaran akan mempengaruhi keberhasilan pembelajaran dan menciptakan suasana kelas lebih hidup dan bermakna.

Hasil uji chi square menunjukkan bahwa mahasiswa yang mempunyai pengetahuan dan sikap yang baik berpengaruh terhadap tingkat partisipasi mahasiswa secara signifikan $(\mathrm{p}<0,05)$. Metode pembelajaran TBL menuntut keaktifan mahasiwa dalam proses pembelajaran. Partisipasi siswa dapat terjadi apabila dalam proses pembelajaran tercipta suatu kondisi yang dapat merangsang keaktifan dan partisipasi siswa ${ }^{9}$. Proses pembelajaran yang kondusif dapat terjadi bila mahasiswa mengetahui mengenai proses pembelajaran yang akan dijalani dan menimbulkan sikap yang positif terhadap proses pembelajaran tersebut. Introduksi sebelum kegiatan pembelajaran bertujuan agar peserta didik mengetahui program kegiatan yang akan dilakukan sehingga menimbulkan sikap positif peserta didik serta mendorong peserta didik untuk berpartisipasi dalam proses pembelajaran.

Salah satu faktor yang mempengaruhi tingkat partiisipasi dalam proses belajar mengajar adalah metode yang digunakan ${ }^{9}$. Metode yang mampu memotivasi mahasiswa untuk mengikuti proses belajar mengajar akan meningkatkan tingkat partisipasi siswa dalam kegiatan tersebut. Motivasi mahasiswa dapat dibangun sejak masa introduksi sehingga mahasiswa memahami apa yang harus dilakukan dalam proses belajar.

Pengetahuan dapat membentuk keyakinan tertentu, sehingga orang berperilaku sesuai dengan keyakinan tersebut ${ }^{10}$. Sikap dapat dirumuskan sebagai kecenderungan untuk merespon (secara positif atau negatif) terhadap orang, objek atau situasi tertentu. Sikap mengandung suatu penilaian emosional (senang, benci, sedih dsb), disamping komponen pengetahuan tentang 
objek serta aspek kecenderungan bertindak ${ }^{8}$. Sikap seseorang dapat berubah dengan diperolehnya tambahan informasi tentang objek tersebut, melalui persuasi serta tekanan dari kelompok sosialnya. Salah satu wujud tanggung jawab atas kewajibannya, pendidik dituntut memilih metode pembelajaran yang paling akomodatif dan kondusif untuk mencapai sasaran dan filosofi pendidikan ${ }^{11}$.

Pembelajaran dengan metode pembelajaran team based learning dapat meningkatkan keterlibatan mahasiswa dalam proses kegiatan belajar dibandingkan menggunakan metode pembelajaran konvensional (teacher centered learning ) ${ }^{2}$. Metode pembelajaran TBL mendorong mahasiswa lebih "friendly" dengan anggota kelompok yang lain untuk mencapai tujuan pembelajaran dan pengembangan keterampilan bekerja sama dalam suatu tim secara aktif. Metode team based learning lebih menarik minat mahasiswa karena mahasiswa dapat belajar lebih efektif dan bekerja sama dalam tim dengan baik ${ }^{4}$. Manfaat tambahan dari penerapan metode pembelajaran TBL adalah memupuk kerja sama tim, meningkatkan interaksi dosenmahasiswa serta meningkatkan umpan balik staf pengajar pada konten dan masalah pemecahan proses ${ }^{12}$. Kerjasama tim menjadi poin terpenting dalam layanan keperawatan.

\section{KESIMPULAN}

1. Mahasiswa Akes Karya Hudasa mempunyai pengetahuan dan sikap yang baik mengenai proses belajar mengajar dengan metode pembelajaran TBL.

2. Tingkat partisipasi mahasiswa dalam proses belajar mengejar dengan metode TBL bagus

3. Pengetahuan dan sikap mengenai metode pembelajaran TBL mempengaruhi tingkat partisipasi mahasiswa dalam proses pembelajaran tersebut.

\section{SARAN :}

1. Setiap awal proses pembelajaran dosen sebaiknya memberikan penjelasan mengenai metode pembelajaran yang akan digunakan dan memotivasi mahasiswa agar berpartisipasi aktif dalam proses pembelajaran

2. TBL dapat digunakan sebagai salah satu alternatif metode pembelajaran dalam pendidikan keperawatan karena mempunyai dampak keterampilan bekerjasama dalam suatu tim.

\section{DAFTAR PUSTAKA}

1. Mody Sheila K, Jessica Kiley, Lori Gawron, Patricia Garcia, Cassing Hammond.(2012). Team-based learning: a novel approach to medical student education in family planning. Elsevier Health Sciences.: 239-242.

2. Jafari, Zahra. (2014). A Comparison Of Conventional Lecture and Team Based Learning methods in terms of student Learning and teaching satisfation. Medical Journal of The Islamic Republic Of Iran : http://mjiri.iums.ac.ir

3. Gaspersz, V, (2003). Metode Analisis untuk Peningkatan Kualitas. Gramedia Pustaka Utama, Jakarta.

4. Samad Arshad Abd, Juridah Md. Rashid, Sharifah Zainab Syd Abd Rahman, Hawanum Hussein (2014), Investigation The Implementation Of Team Based Learning in a University level teacher education course. International Journal of Asian Social Science. Vol : 4 (2) : 249-257

5. Made, Wena. 2011. Strategi Pembelajaran Inovatif Kontemporer. Jakarta: Bumi Aksara.

6. Arends, Richard. 2012. Learning to Teach. Ninth Edition. New York: McGrawHill.

7. Sarwono, Solita, 1993, Sosiologi Kesehatan : Beberapa Konsep beserta Aplikasinya, Yogyakarta : Gadjah Mada Press 
8. Munthe, Bermawi. 2009. Desain Pembelajaran. Yogyakarta: Pustaka Insan Madani.

9. Yamin, Martinis. 2007. Profesionalisasi Guru \& Implementasi KTSP. Jakarta: Gaung.

10. Notoatmodjo, Soekidjo, 2003, Pendidikan dan Perilaku Kesehatan, Jakarta : Rineka Cipta.

11. Handoko, T.H. 2005, Manajemen Personalia dan Sumber Daya Manusia, BPFE, Yogyakarta.

12. Hasil penelitian Nancy et al (2008) menyatakan bahwa 